\title{
Unilateral Double Plantaris Muscle: A Rare Anatomical Variation
}

\author{
Músculo Plantar Doble Unilateral: Una Rara Variación Anatómica
}

David M. Kwinter; James P. Lagrew; Julie, Kretzer; Cara Lawrence; Diksha Malik; Megan Mater \& Jennifer K. Brueckner

KWINTER, D. M.; LAGREW, J. P.; KRETZER, J.; LAWRENCE, C.; MALIK, D.; MATER, M.; BRUECKNER, J. K. Unilateral

double plantaris muscle: a rare anatomical variation. Int. J. Morphol., 28(4):1097-1099, 2010.

SUMMARY: The occurrence of a unilateral second plantaris muscle was discovered during the anatomical dissection of a 47 year old female with Huntington Chorea Disease. The cadaver was found to possess bilateral plantaris muscles and a distinct anomalous muscle morphologically resembling a second plantaris on the medial right leg. The inner and outer bellies of the anomalous plantaris arose proximally from the medial condyle of the femur and formed a short tendon that fused distally with the tendon of the lateral plantaris muscle.

KEY WORDS: Plantaris muscle; Anatomical variation.

\section{INTRODUCTION}

The plantaris muscle is a small, superficial posterior compartment muscle of the lower leg. It has a proximal attachment to the lateral condyle of the femur superior to the gastrocnemius and a distal attachment that is usually fused to the calcaneal tendon (Achilles tendon), but occasionally inserts directly on the medial side of the calcaneous (Szaro et al., 2009). The attachments indicate that the muscle is both a weak flexor of the knee, and plantarflexor. However, it is commonly believed to be a vestige of a muscle that once had attachment to the plantar aponeurosis as is seen in some quadrupedal primates (Keith, 1929) to assist in grasping similar to palmaris longus muscle (Daseler \& Anson, 1943).

Absence of the plantaris muscle is common, with agenesis reported in $8.2 \%$ of male legs and $5.8 \%$ of female legs (Daseler \& Anson). Bilateral absence is also common, occurring in 13 of 50 specimens found to be lacking a plantaris. Unilateral absences have been reported more commonly on the left side than the right (18 left absences versus 6 right absences). In contrast, occurrence of double unilateral or bilateral plantares is exceedingly rare. In separate studies of 520, 750 and 1400 legs, none were reported (Daseler \& Anson). However, a routine dissection recently revealed bilateral double plantares muscles in a 45 year old male (Rana et al., 2006).

\section{CASE REPORT}

An anomalous unilateral double plantaris muscle was found during the routine dissection of a 47 year old female cadaver as part of a medical education program. The muscle was meticulously displayed by dissection and delineation of neighboring structures. The specimen was measured morphometrically and photographed.

\section{OBSERVATIONS}

The positions of proximal attachment of both right leg plantaris muscles were measured with calipers relative to the position of their fused tendon and are expressed in millimeters and as multiples of biepicondylar breadth of the femur. The proximal insertion of the anomalous medial plantaris muscle $(117 \mathrm{~mm}, 1.44)$ was superior to the lateral plantaris muscle (103 mm, 1.27) (Fig. 1). The common tendon traveled between the soleus and gastrocnemius muscles to within $1 \mathrm{~cm}$ of the medial side of the calcaneus where it then split sending fibers anterolaterally to calcaneal attachments (Fig. 2). The main tendon split forming three distinct attachments on the posteromedial side of the calcaneous anterior to the medial side of the calcaneal tendon (Fig. 3). 


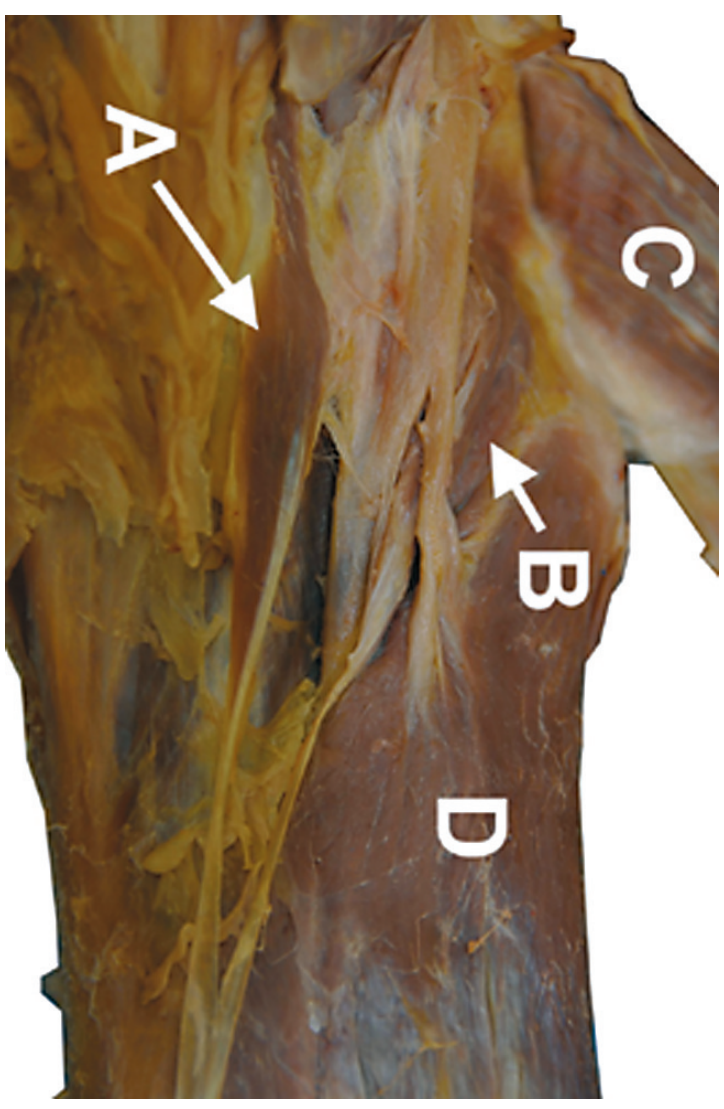

Fig. 1. Posterior view of dissected superior lower right leg. A. Anomalous medial plantaris muscle. B. Typical lateral plantaris muscle. C. Lateral head of gastrocnemius muscle, reflected. D. Soleus muscle.

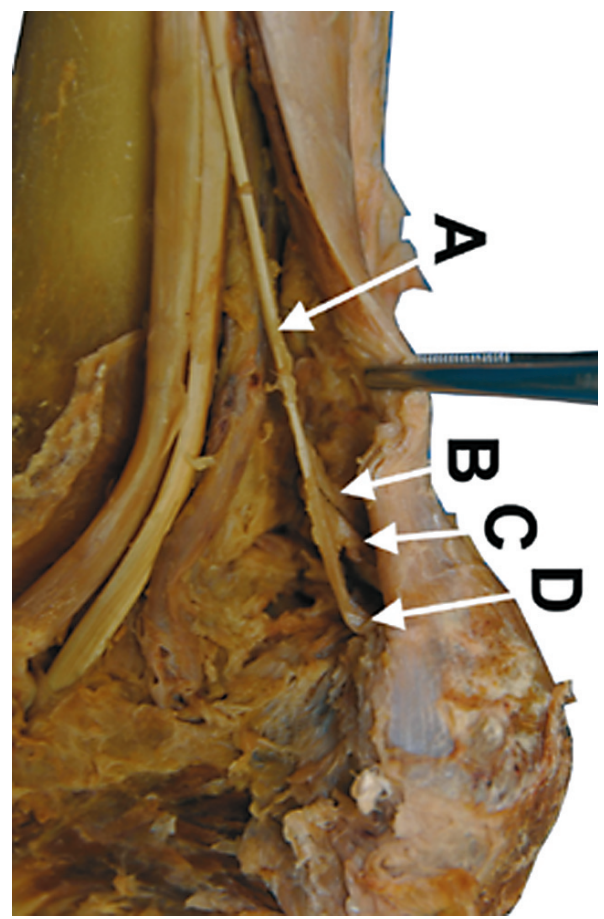

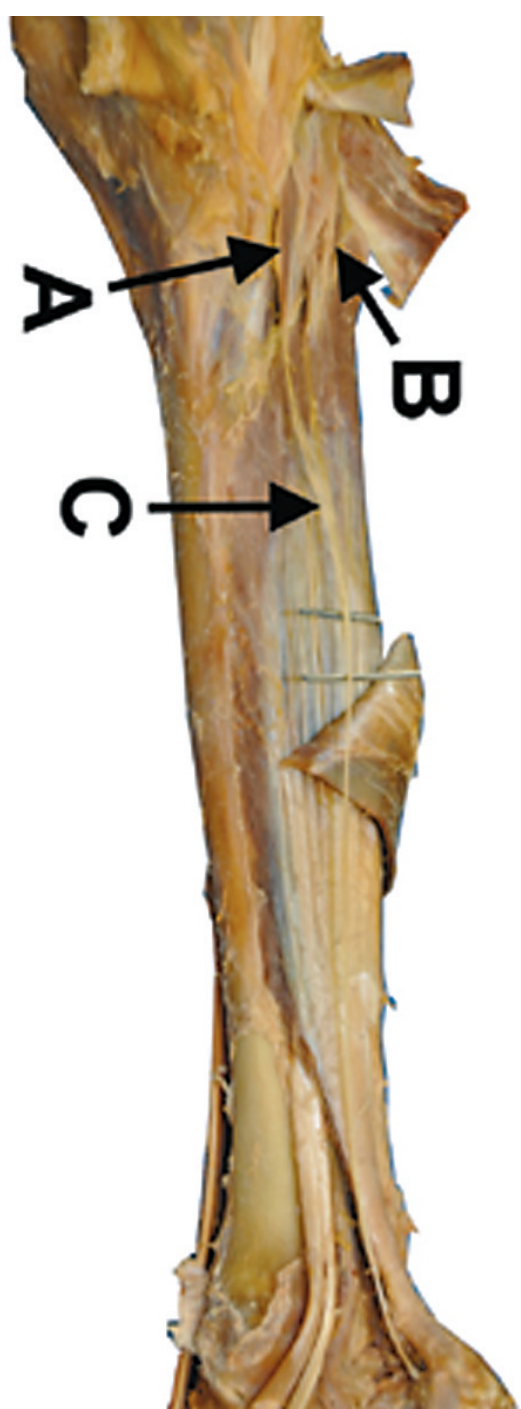

Fig. 2. Medial view of dissected lower right leg. A. Anomalous medial plantaris muscle. B. Typical lateral plantaris muscle. C. Fused plantaris muscle tendon.

Fig. 3. Medial view of dissected Achilles tendon. A. Fused plantaris muscle tendon. BD. Distal plantaris muscle tendonous calcaneal attachments. 
The typical plantaris muscle observed on the left leg had a proximal attachment on the lateral condyle of the femur. Its tendon traveled in an anteromedial course between the soleus and gastrocnemius muscles, wrapping superficial to the gastrocnemius briefly, before attaching independently to the calcaneous anterior to the medial side of the calcaneal tendon.

\section{DISCUSSION}

The plantaris muscle commands interest from a phylogenetic perspective. It has been suggested that the plantaris is a vestigial remnant of human's quadrupedal ancestry. It is believed that the muscle originally attached to the plantar aponeurosis as seen in the American Bear and that the distal attachment has migrated proximally with the onset of bipedalism (Daseler \& Anson).
The plantaris tendon has elicited further interest because of its potential use as a graft (Simpson et al., 1991). Removal of the plantaris muscle does not typically hinder the patient's lower extremity function in the presence of a normal soleus and gastrocnemius. Surgeons have recognized the notable tensile strength of the tendon. They have used the structure successfully in flexor tendon replacement in the hand and have suggested its use in atrioventricular valve repair (Shuhaiber \& Shuhaiber, 2003).

Clinically, the plantaris muscle is primarily of concern in the differential diagnosis of lower extremity pain as its rupture is indistinguishable from deep vein thrombosis without the assistance of high resolution ultrasound or MRI (Lopez et al., 2009). Due to the infrequency of the double plantaris variation, it is not possible to estimate the predisposition of extra plantaris muscles to rupture. However, the presence of variations should remind physicians that this unpredictable anatomy requires careful examination in cases of unexplained lower leg pain.

KWINTER, D. M.; LAGREW, J. P.; KRETZER, J.; LAWRENCE, C.; MALIK, D.; MATER, M.; BRUECKNER, J. K. Músculo plantar doble unilateral: una rara variación anatómica. Int. J. Morphol., 28(4):1097-1099, 2010.

RESUMEN: Un segundo músculo plantar unilateral fue descubierto durante una disección anatómica de rutina, en una mujer de 47 años de edad con Enfermedad de Huntington Chorea. En la cara medial de la piena derecha, el cadáver presentaba, bilateralmente, el músculo plantar y un músculo anómalo, morfológicamente distinto, que se asemejaba a un segundo músculo plantar. Los vientres medial y lateral del músculo plantar anómalo se originaban del cóndilo medial del fémur y formaban un tendón corto que se fusionaba con el tendón del músculo plantar lateral.

PALABRAS CLAVE: Músculo plantar; Variación anatómica.

\section{REFERENCES}

Daseler, E. H. \& Anson, B. J. The Plantaris Muscle: An Anatomical Study of 750 Specimens. J. Bone Joint Surg. Am., 25: 822-7, 1943.

Keith, A. The history of the human foot and its bearing on orthopaedic practice. J. Bone Joint Surg. Am., 11:10-32, 1929.

Lopez, G. J.; Hoffman, R. S. \& Davenport, M. Plantaris rupture: A mimic of deep venous thrombosis. J. Emerg. Med., Article in Press, 2009.

Rana, K. K.; Das, S. \& Verma, R. Double Plantaris Muscle: A Cadaveric Study with Clinical Importance. Int. J. Morphol., 24(3):495-8, 2006.

Shuhaiber, J. H. \& Shuhaiber, H.H. Plantaris tendon graft for atrioventricular valve repair. A novel hypothetical technique. Tex. Heart Inst. J., 30:42-4, 2003.
Simpson, S. L.; Hertzog, M. S. \& Barja, R. H. The plantaris tendon graft: an ultrasound study. J. Hand Surg. Am., 16: 708-11, 1991.

Szaro, P.; Witkowski, G.; Smigielski, R.; Krajewski, P. \& Ciszek, B. Fascicles of the adult human Achilles tendonan anatomical study. Ann. Anat., 191:586-93, 2009.

\author{
Correspondence to: \\ David M. Kwinter \\ University of Kentucky College of Medicine \\ 138 Leader Avenue \\ 40506-9983 \\ Lexington, Kentucky \\ USA
}

Phone: (859) 323-5261

E-mail: jennifer.brueckner@uky.edu

Received: 01-08-2010

Accepted: 29-09-2010 
